\title{
3D Printing for 21st Century Medical Learners: Opportunities for Innovative Research and Collaboration
}

\author{
AiLi Wang ${ }^{1}$, Talia Chung ${ }^{2}$, Hanan Anis $^{3}$, Alireza Jalali ${ }^{1}$ \\ ${ }^{1}$ Faculty of Medicine, University of Ottawa \\ 2 Health Sciences Library, University of Ottawa \\ ${ }^{3}$ Faculty of Engineering, University of Ottawa
}

ABSTRACT

With the commercializaton of accessible 3D printers, using 3D printng for creation of personalized medical interventons has become a rapidly expanding area of research. In keeping with these developments, the Faculty of Medicine at the University of Ottawa has purchased 3D printers (Makerbot Replicator 2X and Ultmaker 2 Extended + ) and launched a collaboration with Makerspace and the Health Sciences Library to investgate local opportunites to incorporate 3D printng into education, simulations and research. This artcle aims to summarize some of the recent developments in 3D printng and introduce readers to how one could use 3D printng for personalized medicine.

RÉSUMÉ

Avec la venue de la commercialisaton d'imprimantes 3D accessibles, l'emploi de l'impression 3D pour la création d'interventons médicales personnalisées est un domaine de recherche en développement rapide. Afin de rester à jour avec ces développements, la Faculté de Médecine de I'Université d'Ottawa s'est procuré des imprimantes 3D (Makerbot Replicator 2X et Ultmaker 2 Extended +) et a entamé une collaboration avec Makerspace et la Bibliothèque des Sciences de la Santé, pour examiner des opportunités locales visant à incorporer l'impression 3D à l'éducaton, aux simulations et à la recherche. Cet article vise à résumer certains des développements récents en impression 3D et à présenter aux lecteurs la manière dont celle-ci peut être utlisée pour la médecine personnalisé.

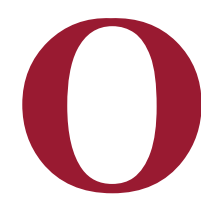

ne of the latest trends to inspire creatve minds is $3 \mathrm{D}$ printng. While printing in more than two dimensions has been possible since the 1980s, the recent reduction in cost and increase in accuracy and accessibility has made 3D printing much more appealing for the average consumer. The resulting boom in user base has made 3D designs available online for tools, toys, jewelry and even guns, which has sparked quite a bit of controversy (1). However, 3D printing is not just an innovation for hobbyists, it also opens doors for experts in other fields who may have ideas that they wish to turn into tangible reality - a particularly useful opportunity for prototyping and the development of personalized medicine with end-products that can be tailored to an individual's needs. In keeping with this, the Faculty of Medicine at the University of Ottawa has launched a collaboration with the Engineering Makerspace and the Health Sciences Library to bring 3D printing to medicine. So, as a student with access to desktop printers, what can you make? What should you expect?

Keywords: 3D printing

\section{TYPES OF 3D PRINTERS}

Automated production of physical objects from 3-dimensional computer-aided design (3D CAD) models, often called rapid prototyping, is possible through several approaches (2). The term "3D printing" in particular refers to an additive technique that builds products layer-by-layer using a series of cross-sectional images. It is very much like a traditional ink printer with a material that can be built up vertically. How one would 3D print an object would depend on the 3D printer one has available, the most common methods being stereolithography (SLA) and fused deposition modeling (FDM) (3). In SLA printing, the liquid polymer is turned solid layer-by-layer along the paths of a laser beam. In selective laser sintering (SLS), a similar process using lasers is conducted on powdered polymer rather than liquid (3). In FDM printers, a thermoplastic polymer is extruded from the printer head as a paste that solidifies and forms the base for the next layer (3). The two printers purchased by the Faculty of Medicine are both small desktop FDM models (Makerbot Replicator $2 X$ and Ultimaker 2 Extended +) compatible with a range of different thermoplastic filaments with varying physical properties. 


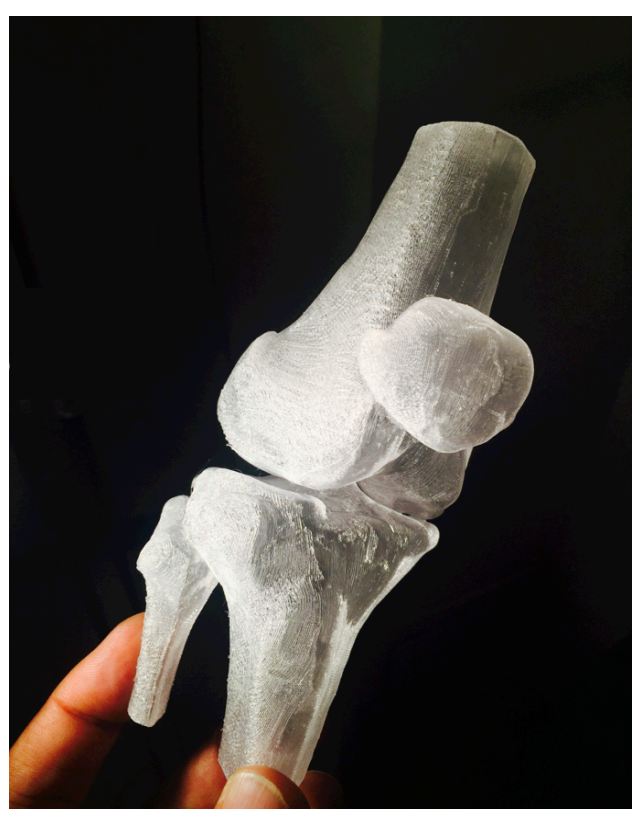

Figure 1. A knee joint printed with clear 3D filaments tglase on a Makerbot Replicator $2 \mathrm{X}$ at the University of Ottawa. The knee joint model was extracted from computed tomography (CT) data.

\section{APPLICATIONS OF 3D PRINTING}

With the basics of 3D printing explained, it is not hard to see that just like regular printing, it could be applied to virtually any field. 3D printers are useful across the field of medicine, particularly in personalized medicine because of the challenge that individualized anatomy poses to medical treatment. While devices like casts and bandages can be fitted to a wide range of body types and sizes, customized products such as prosthetics, implants and even surgical tools must be tailored to a patient's anatomy, risk factors and prognosis $(4,5)$. Additionally, preand perioperative planning for complex surgical operations can be made much easier with physical models, particularly if it requires the joint effort of several surgeons (6-11). For rehabilitation medicine, 3D printed prosthetics and exoskeletons have drastically improved access (5). As an example, a local Ottawa child was able to receive $3 \mathrm{D}$ printed prosthetics that could be modified and adjusted as he grows (12). Furthermore, 3D printing is a great way of modelling anatomical structures in medical training and education to help learners visualize conceptual components in a physical manner, such as with 3D printed prosections of the orbit or the hand (13-15). The current cutting edge research in personalized $3 \mathrm{D}$ printing is the creation of personalized medications - printing customized combination pills at precise doses. Unfortunately, there are no commercially available printers that can perform such a task.

It is important to have realistic expectations when it comes to $3 \mathrm{D}$ printing, since reality is often years behind what is presented in the media. A common issue revolves around material. The desktop printers are only compatible with a limited number of thermoplastic, with only one or two used at a tme, and could block the extruding nozzle quite easily. Sometmes, mechanical challenges when printing with more complex materials such as flexible or transparent polymers can be improved by optimization and careful adjustment of printer components and settings. In other instances, it may be necessary to work in prototypes and use a higher-end printer to produce the final model. Another issue is tme - think of how long your regular inkjet printer takes to print one page, then consider that several hundreds of these "pages" are required to form a full object. Therefore, the bigger, more detailed the model, the longer it takes.

\section{PROCESS OF CREATING CUSTOMIZABLE MODELS}

The first step to $3 \mathrm{D}$ printing is researching the idea to see whether it is feasible with the available printers. The NIH 3D Print Exchange is a starting point for locating existing 3D printing research, as it is the largest database for scientific 3D models (16). Extracting 3D models that correlate with real patient anatomy is possible through medical imaging data and $3 \mathrm{D}$ scanning $(17,18)$ (Figure 1). Medical imaging includes plain Xray films, computed tomography $(\mathrm{CT})$, magnetic resonance imaging (MRI) and ultrasound. Of these, it is possible to obtain CT, MRI and ultrasound in 3D formats, so long as the source scan is sufficiently thinly sliced. In hospitals and clinics, these data are stored in Digital Imaging and Communications in Medicine (DICOM) files, which are a series of scanned images that can be converted into 3D files with software (17). Just like interpreting regular imaging data, $\mathrm{CT}$ scans are best for bones while MRIs and ultrasounds are better for soft tissue. If you need visualization of blood vessels, the best approach will be an angiogram, which uses CTs or MRls with contrast dye to highlight the vessels. However, image series that have thick slices can create significant distortion in the model when extracted. 3D scanning, on the other hand, is able to map external features at points in space, but lacks the ability to render internal anatomy.

To create new models or to alter existing models requires $3 \mathrm{D}$ CAD software programs, of which there are many available - the most common being Google Sketchup and Blender. In these 
computer programs, the models are represented by a group of points in space that can be exported as stl files, which are formed by interconnected triangles and make up the standard supported file type for most 3D printers.

\section{D PRINTING AT THE HEALTH SCIENCES LIBRARY}

Since early 2015, the Faculty of Engineering's Makerspace and the Health Sciences Library have been offering 3D printing workshops at the University's downtown campus and at its Roger Guindon Pavillon (RGN) which houses the faculties of medicine and health sciences. The workshops held at RGN have been very popular, indicating a high level of interest among medical students and researchers in the applications of 3D printing to medicine. Prior to this initiative, 3D printers were available to students at the Faculty of Engineering building, located at the downtown campus; but with the Faculty of Medicine's purchase of 3D printers, medical students now have greater access to 3D printing technology within proximity to their professors and classes. As part of the Health Sciences Library's pilot project to offer 3D printing-on-demand, researchers in affiliated hospitals have requested models for proteins being studied and medical students have used the NIH 3D Print Exchange model database to locate anatomical models for printing. Although the traditional notion of libraries is largely associated with silent study and shelves upon shelves of books, contemporary library spaces and services are increasingly oriented to providing digital research tools and materials, group collaboration spaces, and support for independent learners. As a place where ideas and individuals intersect, could 3D printing in the Health Sciences Library act as a catalyst for the development of a community of students, researchers and healthcare practitioners with a shared interest in MakerHealth technologies?

\section{CONCLUSION}

In the field of personalized medicine, 3D printing holds tremendous opportunities for innovative research and collaboration. Whether designing protein structures to demonstrate drug interactions, extracting anatomical models for surgical preparation, or creating customized prostheses, the average person can make a difference with desktop 3D printers. As with other technological translations into clinical practice, buy-in from medical professionals is a critical factor to the adoption of 3D printing for future progress. So why not try your hands at it today?
For further information on 3D printng, please visit the University of Ottawa Health Sciences website at biblio.uOttawa.ca/en/ health-sciences-library/3d-printng

\section{REFERENCES}

1. Blackman J. The 1st Amendment, 2nd Amendment, and 3D Printed Guns. Tenn Law Rev. 2014;81(479):479-538.

2. Negi S, Dhiman S, Sharma RK. Basics and applications of rapid prototyping medical models. Rapid Prototyp J. 2014;20(3):256-267.

3. Srivastava M, Utkarsh, Yashaswi R. Trends in the Domain of rapid Prototyping: A Review. Int J Mech Robot Res. 2014;3(3).

4. Ventola CL. Medical Applications for 3D Printing: Current and Projected Uses. P T. 2014;39(10):704-711.

5. Bhatia SK, Sharma S. 3D-printed prosthetics roll off the presses. Chem Eng Prog. 2014;110(5):28-33.

6. Giovinco NA, Dunn SP, Dowling L, et al. A Novel Combination of Printed 3-Dimensional Anatomic Templates and Computer-assisted Surgical Simulation for Virtual Preoperative Planning in Charcot Foot Reconstruction. J Foot Ankle Surg. 2012;51(3):387-393.

7. Jacobs S, Grunert R, Mohr FW, Falk V. 3D-Imaging of cardiac structures using 3D heart models for planning in heart surgery: a preliminary study. Interact Cardiovasc Thorac Surg. 2008;7(1):6-9.

8. Kurenov SN, Ionita C, Sammons D, Demmy TL. Three-dimensional printing to facilitate anatomic study, device development, simulation, and planning in thoracic surgery. J Thorac Cardiovasc Surg. 2015;149(4):973-979.e1.

9. Schwartz A, Money K, Spangehl M, et al. Office-based rapid prototyping in orthopedic surgery: a novel planning technique and review of the literature. Am J Orthop (Belle Mead NJ). 2015;44(1):19-25.

10. Thomas DJ, Azmi MABM, Tehrani Z. 3D additive manufacture of oral and maxillofacial surgical models for preoperative planning. Int J Adv Manuf Technol. 2014;71(9-12):1643-1651.

11. Silberstein JL, Maddox MM, Dorsey P, Feibus A, Thomas R, Lee BR. Physical models of renal malignancies using standard cross-sectional imaging and 3-dimensional printers: A pilot study. Urology. 2014;84(2):268-272.

12. Spears, T. Meet the Ottawa boy who's about to get a new hand (with video) [Internet]. Ottawa Citizen; 2015 Mar 18. [updated 2015 Mar 18; cited 2016 Apr 2] Available from: http://ottawacitizen.com/news/local-news/meetthe-ottawa-boy-whos-about-to-get-a-new-hand/.

13. Adams JW, Paxton L, Dawes K, Burlak K, Quayle M, McMenamin PG. 3D printed reproductions of orbital dissections: a novel mode of visualising anatomy for trainees in ophthalmology or optometry. $\mathrm{Br} \mathrm{J}$ Ophthalmol. 2015:1162-1167.

14. Gharenazifam M, Arbabi E. Anatomy-based 3D skeleton extraction from femur model. J Med Eng Technol. 2014;38(8):402-410.

15. Mcmenamin PG, Quayle MR, Mchenry CR, Adams JW. The production of anatomical teaching resources using three-dimensional (3D) printing technology. Anat Sci Educ. 2014;7(6):479-486.

16. National Institutes of Health. NIH 3D Print Exchange [Internet]. U.S. Department of Health and Human Services [cited 2016 Feb 29]. Available from: http://3dprint.nih.gov/

17. Mitsouras $D$, Liacouras $P$, Imanzadeh A, et al. Medical 3D Printing for the Radiologist 1. 2015;(November).

18. Rengier F, Mehndiratta A, Von Tengg-Kobligk H, et al. 3D printing based on imaging data: Review of medical applications. Int J Comput Assist Radiol Surg. 2010;5(4):335-341. 